\title{
Thermoplasticity in Polyurethane-Imide Elastomers
}

\author{
Tomohiro Ueda, Shin-Ichi Inoue \\ Department of Applied Chemistry, Aichi Institute of Technology, Toyota, Japan \\ Email:w15801ww@aitech.ac.jp
}

How to cite this paper: Ueda, T. and Inoue, S.-I. (2018) Thermoplasticity in Polyurethane-Imide Elastomers. Open Journal of Polymer Chemistry, 8, 11-20. https://doi.org/10.4236/ojpchem.2018.81002

Received: November 29, 2017

Accepted: February 23, 2018

Published: February 26, 2018

Copyright $\odot 2018$ by authors and Scientific Research Publishing Inc. This work is licensed under the Creative Commons Attribution International License (CC BY 4.0).

http://creativecommons.org/licenses/by/4.0/

\begin{abstract}
Polyurethane-imide elastomers (PUIEs) are formed from isocyanates, polyols, diamines, and acid anhydrides through liquid polymerization. However, thermoplastic PUIEs have rarely been reported because the synthesis of thermoplastic PUIEs remains a challenge in polymer chemistry. In this study, PUIEs were prepared from 4,4'-diphenylmethane diisocyanate, polyols (polytetramethylene glycol $(\mathrm{Mw}=1000)$, polycaprolactone diol $(\mathrm{Mw}=1000)$, and polycarbonate diol $(\mathrm{Mw}=1000)$ ), 4,4'-oxydianiline, and acid anhydrides (pyromellitic dianhydride and 4,4'-oxydiphtaric anhydride). The thermoplasticities of the resultant PUIEs were investigated, and only PUIEs synthesized using 4,4'-oxydiphtaric anhydride expressed thermoplasticity.
\end{abstract}

\section{Keywords}

Polyurethane-Imide Elastomer, Polyol, Acid Anhydride, Morphology, Chemical and Physical Properties

\section{Introduction}

Polyurethane (PU) has been widely used in a variety of applications in many different fields. In general, PU suffers from heat resistance. However, by improving this fundamental property, PU may gain some industrial advantages. Therefore, chemists have actively pursued PU heat resistance. Polyurethane-imide (PUI), which has stability in high-temperature environments, excellent electrical and mechanical properties, and good chemical resistance, can be prepared via an organic-organic hybrid between urethanes and imides [1]-[18]. PUI possesses some distinct properties such as heat resistance and solvent resistance. Therefore, PUI has found special applications in selected industries and continues to gain importance in a variety of applications. PUI is used in a surprising number of commercial applications. For convenience, PUI is classi- 
fied into three major types of products: foams [19] [20] [21] [22], elastomers [23]-[30], and resins [5] [31] [32] [33]. However, a particularly interesting material is polyurethane-imide elastomer (PUIE). We focused on PUIE because it is a novel heat-resistant elastomer that is widely used for commercial products, and we were successful in improving the synthetic method for creating PUIEs [4] [9] [15]. Moreover, we focused on thermoplastic PUIEs (TPUIEs) that could be utilized as industrial materials. Some of the most important TPUIE attributes include their ability to be reprocessed, the wide range of colors obtainable, and their worldwide availability. Although TPUIEs are industrially utilized, they are often reported on in the field of PUIEs. From both the theoretical and practical standpoints, it is important to synthesize TPUIEs that maintain their thermoplasticity. This becomes a key challenge in the field of polymer chemistry, and it is important that an expression of PUIE thermoplasticity is clarified.

In this article, we used the following materials for the synthesis of new PUIEs: 4,4'-diphenylmethane diisocyanate, polyols (polytetramethylene glycol $(\mathrm{Mw}=$ $1000)$, polycaprolactone $(\mathrm{Mw}=1000)$, and polycarbonate diol $(\mathrm{Mw}=1000))$, 4,4'-oxydianiline, and acid anhydrides (pyromellitic dianhydride and 4,4'-oxydiphthalic anhydride). The resulting thermoplasticities were examined.

\section{Experimental}

\subsection{Materials}

4,4'-Diphenylmethane diisocyanate (MDI) and polyols (polytetramethylene glycol $(\mathrm{Mw}=1000)(\mathrm{PTMG1000})$, polycaprolactone diol $(\mathrm{Mw}=1000)(\mathrm{PCL} 1000)$, and polycarbonate diol $(\mathrm{Mw}=1000)(\mathrm{PCD} 1000))$ were supplied by Tosoh Industry, and they were purified by distillation or dried prior to use. Pyromellitic dianhydride (PMDA), 4,4'-oxydiphtaric anhydride (ODPA), and 4,4'-oxydianiline (ODA) were purchased from Tokyo Chemical Industry. $\mathrm{N}$-Methyl-2-pyrrolidone (NMP) was purchased from Nacalai Tesque, Inc., purified by distillation, and stored over $4 \AA ̊$ molecular sieves.

\subsection{Synthesis}

Scheme 1 shows our synthetic method for preparing the PUIEs. Table 1 summarizes the composition of the PUIE composites. All the PUIEs were prepared by liquid polymerization. PUIEs containing $35 \%$ polyimide were synthesized. MDI and polyols (PTMG1000, PCL1000, and PCD1000) were placed in a 100 $\mathrm{mL}$ four-necked separable reaction flask equipped with a mechanical stirrer, a gas inlet tube, and a reflux condenser, and the mixture was stirred at $80^{\circ} \mathrm{C}$ for 30 min. To this reaction mixture was added PMDA and NMP $(15 \mathrm{~mL})$, and the mixed solution was stirred at $150^{\circ} \mathrm{C}$ for $15 \mathrm{~min}$. ODA in NMP $(10 \mathrm{~mL})$ was added, and the mixture was then stirred at $150^{\circ} \mathrm{C}$ for another $2 \mathrm{~h}$. The reaction was carried out under an Ar atmosphere. A test film was next prepared from the synthesized PUIEs by casting half of the obtained polymer solution using a centrifugal casting machine at $150^{\circ} \mathrm{C}$ overnight, after which the film was treated at $200^{\circ} \mathrm{C}$ for $4 \mathrm{~h}$ in vacuo $(267-400 \mathrm{~Pa})$. 
<smiles>O=C1OC(=O)c2cc(Oc3ccc4c(c3)C(=O)OC4=O)ccc2C1=O</smiles>

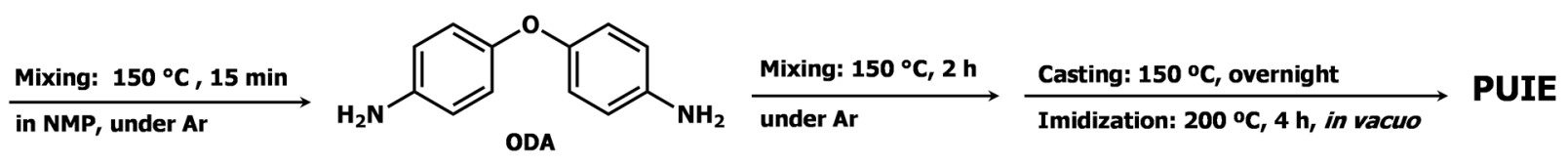

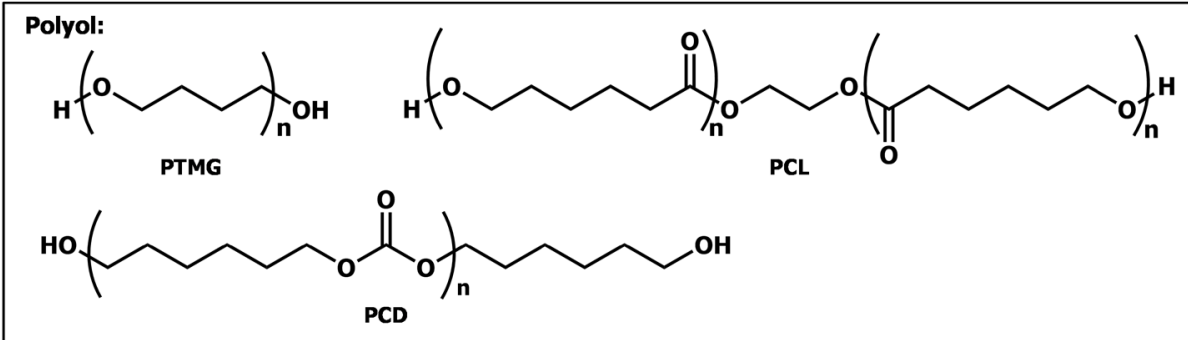

Scheme 1. Solution-phase synthesis of PUIEs.

Table 1. Synthesis of PUIEs.

\begin{tabular}{cccccc}
\hline Sample & $\begin{array}{c}\text { MDI }^{\mathrm{a}} \\
\left(\times 10^{-3} \mathrm{~mol}\right)\end{array}$ & $\begin{array}{c}\text { Polyol }^{\mathrm{b}} \\
\left(\times 10^{-3} \mathrm{~mol}\right)\end{array}$ & $\begin{array}{c}\text { ODA }^{\mathrm{c}} \\
\left(\times 10^{-3} \mathrm{~mol}\right)\end{array}$ & $\begin{array}{c}\text { PMDA }^{\mathrm{d}} \\
\left(\times 10^{-3} \mathrm{~mol}\right)\end{array}$ & $\begin{array}{c}\text { ODPA }^{\mathrm{e}} \\
\left(\times 10^{-3} \mathrm{~mol}^{2}\right)\end{array}$ \\
\hline PUIE-PMDA & 4.40 & 2.50 & 1.90 & 3.80 & - \\
PUIE-ODPA & 4.08 & 2.50 & 1.57 & - & 3.14 \\
\hline
\end{tabular}

${ }^{\mathrm{a}} 4,4$ '-MDI: $\mathrm{Mw}=250.25$; ${ }^{\mathrm{P} T M G 1000: \mathrm{Mw}}=1000 ;$ PCL1000: $\mathrm{Mw}=1000 ;$ PCD1000: $\mathrm{Mw}=1000 ;{ }^{\mathrm{c} O D A}: \mathrm{Mw}=200.24 ;{ }^{\mathrm{d} P M D A}: \mathrm{Mw}=218.12$.

\subsection{Characterization}

\subsubsection{Chemical Properties}

Swelling tests were carried out using $0.1000 \mathrm{~g}$ test pieces. The degree of swelling (Rs) was calculated using the formula Rs $(\%)=\left(\mathrm{W}^{\prime}-\mathrm{W}\right) / \mathrm{W} \times 100$, where $\mathrm{W}^{\prime}$ is the weight of the test piece soaked in benzene for $24 \mathrm{~h}$, and $\mathrm{W}$ is the weight of the test piece after drying at $30^{\circ} \mathrm{C}$ for $24 \mathrm{~h}$ in vacuo.

\subsubsection{Mechanical Properties}

Tensile tests were performed on an OrientecRTC-1225A (Tokyo, Japan) with a model-U-4300 using a JIS 3-dumbbell as the standard sample and a crosshead speed of $100 \mathrm{~mm} / \mathrm{min}$.

\subsubsection{Thermal Properties}

Differential scanning calorimetry (DSC) measurements were performed on a Rigaku Thermo-Plus DSC-8230 (Tokyo, Japan) at $10^{\circ} \mathrm{C} / \mathrm{min}$ from -120 to $200^{\circ} \mathrm{C}$ under an $\mathrm{Ar}$ atmosphere. Approximately $9.5 \mathrm{mg}$ of each PUIE was weighed and sealed in an aluminum pan. The samples were rapidly cooled to $-120^{\circ} \mathrm{C}$ and then heated to $200^{\circ} \mathrm{C}$ at $10^{\circ} \mathrm{C} / \mathrm{min}$.

Dynamic mechanical analysis (DMA) was performed on a Seiko Instruments DMS 6100 (Chiba, Japan) at $5^{\circ} \mathrm{C} / \mathrm{min}$ over $-100^{\circ} \mathrm{C}$ to $300^{\circ} \mathrm{C}$ at $20 \mathrm{~Hz}$ under a $\mathrm{N}_{2}$ 
atmosphere.

Thermogravimetric analysis (TGA) was performed on a Seiko Instruments TG/DTA6200 device (Chiba, Japan) at a heating rate of $10^{\circ} \mathrm{C} / \mathrm{min}$ from 30 to $500^{\circ} \mathrm{C}$ under a $\mathrm{N}_{2}$ atmosphere.

\subsubsection{Molecular Calculations (Gaussian)}

Molecular calculations were carried out using the Gaussian09W program at the B3LYP/6-31G(d) level. The resulting molecular models were visualized using Gauss View 5.0.

\section{Results and Discussion}

\section{Expression of Thermoplasticity}

The definition of a thermoplastic elastomer in JIS appears to be the following: "A polymer, or blended polymer, showing a vulcanized rubber-like nature at the operating temperature that can be processed and reprocessed to recover the polymer, or blended polymer, at high temperature." Currently, there is no defined test method for evaluating thermoplasticity. Therefore, we defined thermoplasticity as follows: "An elastomer showing elasticity at the operating temperature that can be reprocessed at higher temperatures. Moreover, the nature of the reformed elastomer must demonstrate the same properties as the original material."

Synthesis of the PUIEs was carried out using various raw materials and the PUIE films fused during the process of imidization. A heating test was carried out on the PUIE films (Figure 1). The PUIE films that contained ODPA became fused, whereas the PMDA-containing PUIEs burned and carbonized. This suggests that thermoplasticity only appears in the PUIEs that contained ODPA as the acid anhydride. To confirm the thermoplasticity of PUIEs synthesized with ODPA, a press molding was carried out. Then, tests for the chemical and physical properties (swelling test, tensile test, DSC, DMA, and TGA) of the PUIEs before and after the molding were carried out.

The swelling rate and $T_{\mathrm{g}}$ values of PUIEs both before and after the molding were nearly identical (Table 2). Figures $2-4$ show the stress-strain curves, $\tan \delta$, and $\mathrm{T}_{5 \text { and } 50}$, respectively. The stress-strain curves, $\tan \delta$, and $\mathrm{T}_{5 \text { and } 50}$ of the PUIEs both before and after the molding were also identical.

Table 3 shows that the PUIEs expressed thermoplasticity. It has been suggested that the structure of ODPA in the PUIEs is related to the thermoplasticity. Therefore, to clarify correlation between the thermoplasticity and the structure of the acid anhydride raw material, the molecular orbitals of the PUIEs were calculated using the Gaussian program. ODPA, PMDA, ODPA-containing PUIE, and PMDA-containing PUIE were used as the model chemical compounds. Figure 5 and Figure 6 show the calculated results. The flexibility of the PMDA molecule, which has an aromatic ring and an imide group in the same plane, is relatively low and the molecule is fairly restrained. In contrast, the flexibility of the ODPA molecule, which has an oxygen atom between the two 
ODPA

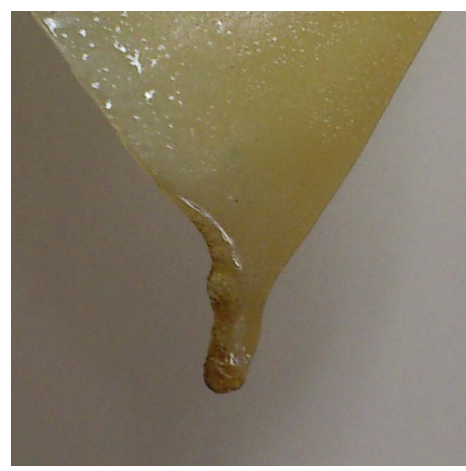

PMDA

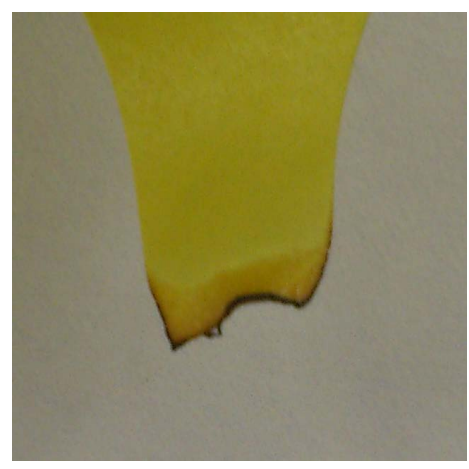

Figure 1. Heating test of PUIEs: PUIE-ODPA and PUIE-PMDA.

Table 2. Synthesis of PUIEs.

\begin{tabular}{ccccc}
\hline Sample & Swelling rate $(\%)$ & $T_{g}^{b}\left({ }^{\circ} \mathrm{C}\right)$ & $T_{5}^{c}\left({ }^{\circ} \mathrm{C}\right)$ & $T_{50}^{c}\left({ }^{\circ} \mathrm{C}\right)$ \\
\hline Before ODPA-PTMG & 235 & -26 & 352 & 432 \\
After ODPA-PTMG & 213 & -25 & 350 & 433 \\
Before ODPA-PCL & 175 & 52 & 324 & 417 \\
After ODPA-PCL & 173 & 50 & 320 & 417 \\
Before ODPA-PCD & 169 & 62 & 328 & 374 \\
After ODPA-PCD & 157 & 64 & 328 & 374 \\
\hline
\end{tabular}

${ }^{\mathrm{a}}$ Measurement conditions: benzene solvent at room temperature $\left(23^{\circ} \mathrm{C} \pm 2{ }^{\circ} \mathrm{C}\right)$ for $24 \mathrm{~h}$; ${ }^{\mathrm{b}} \mathrm{DSC}$ was performed at a heating rate of $10{ }^{\circ} \mathrm{C} / \mathrm{min}$ from $-100^{\circ} \mathrm{C}$ to $300^{\circ} \mathrm{C}$ under an $\mathrm{Ar}$ atmosphere; ${ }^{\circ} \mathrm{TGA}$ was performed at a heating rate of $10^{\circ} \mathrm{C} / \mathrm{min}$ from $30^{\circ} \mathrm{C}$ to $500^{\circ} \mathrm{C}$ under a $\mathrm{N}_{2}$ atmosphere.

(a) PTMG

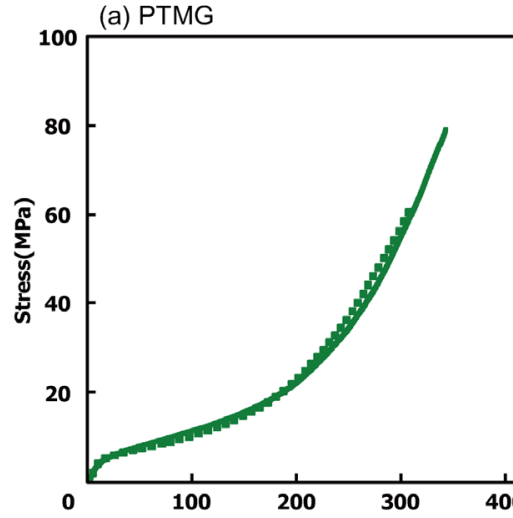

(b) PCL

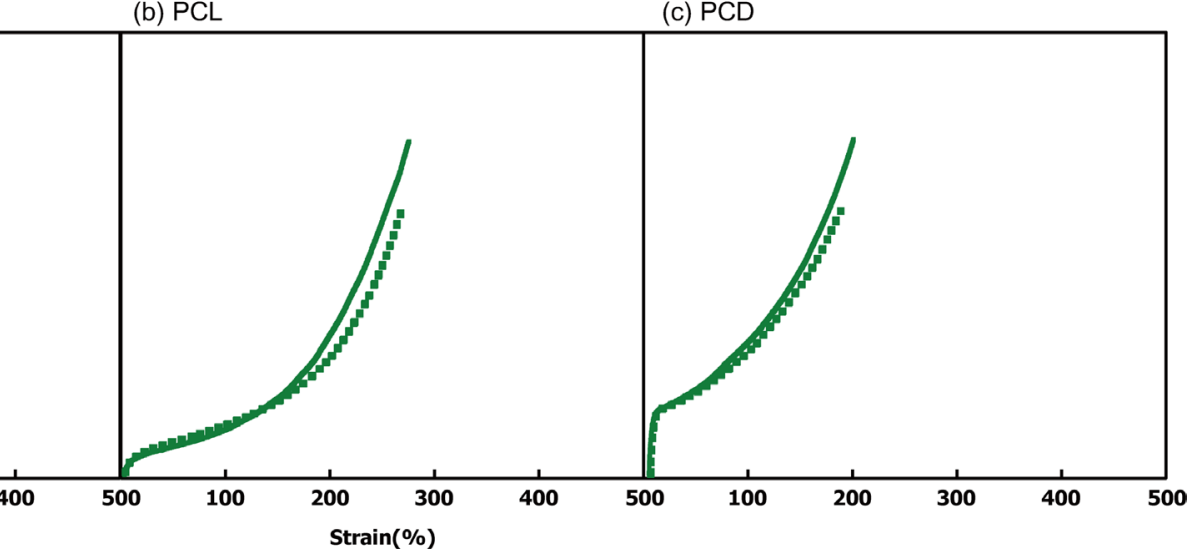

Figure 2. Tensile tests (stress-strain curves) of the PUIEs: solid line (before PUIE-ODPA) and dotted line (after PUIE-ODPA).

aromatic rings, is relatively high and the molecule is not restrained (Figure 5). Moreover, the flexibility of the PUIE is restrained by the $\pi-\pi$ interactions between the diamine (ODA) and the aromatic ring. The expression of thermoplasticity for the ODPA-containing PUIE is thought to be related to the flexibility of the PUIE molecule, and this flexibility results from the molecular structure of ODPA (Figure 5). This concept of thermoplasticity is supported by the swelling tests and the DMA results as well. 
(a) PTMG

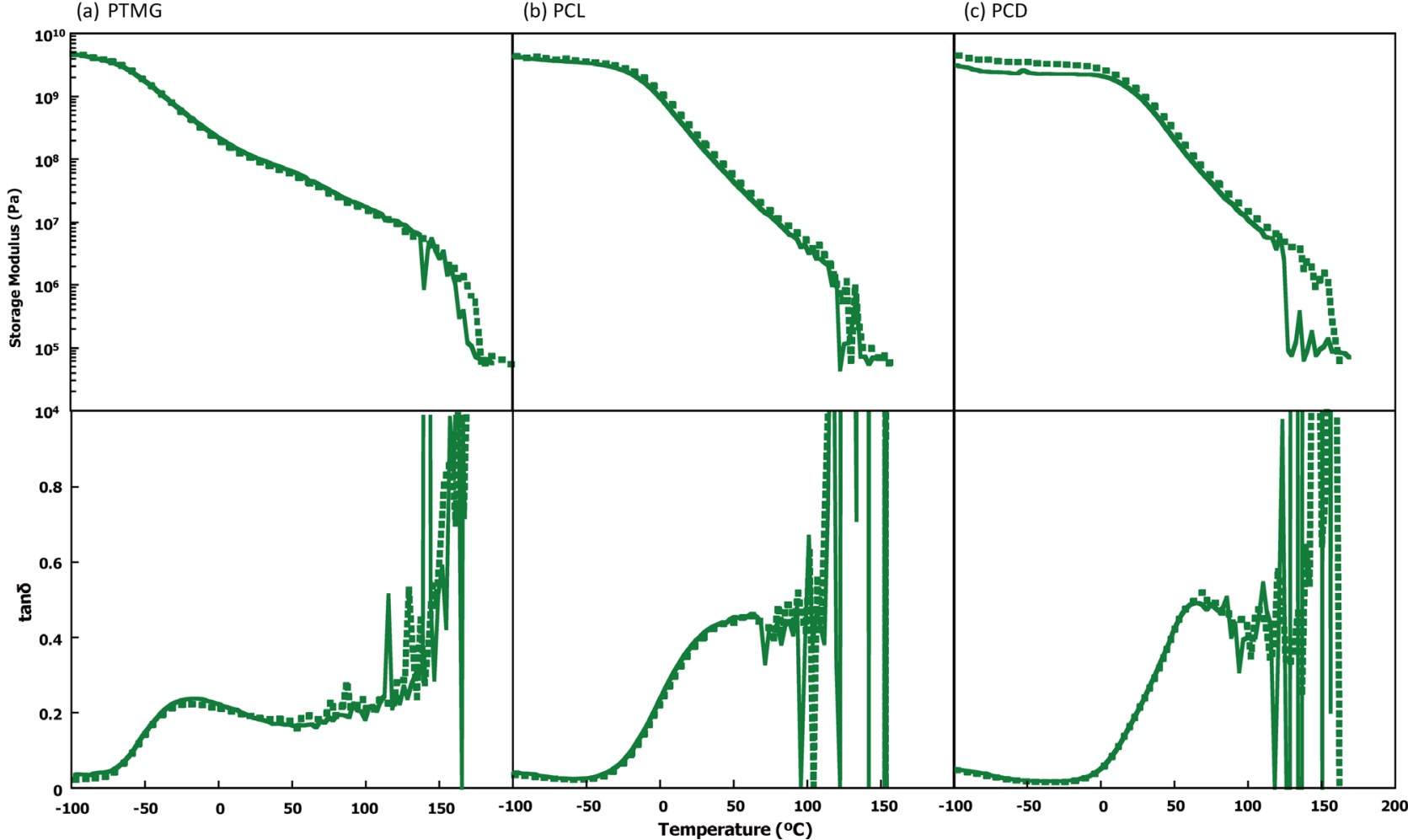

Figure 3. Storage modulus and $\tan \delta$ of the PUIEs as a function of temperature: solid line (before PUIE-ODPA) and dotted line (after PUIE-ODPA).
(a) PTMG
(b) PCL
(c) PCD

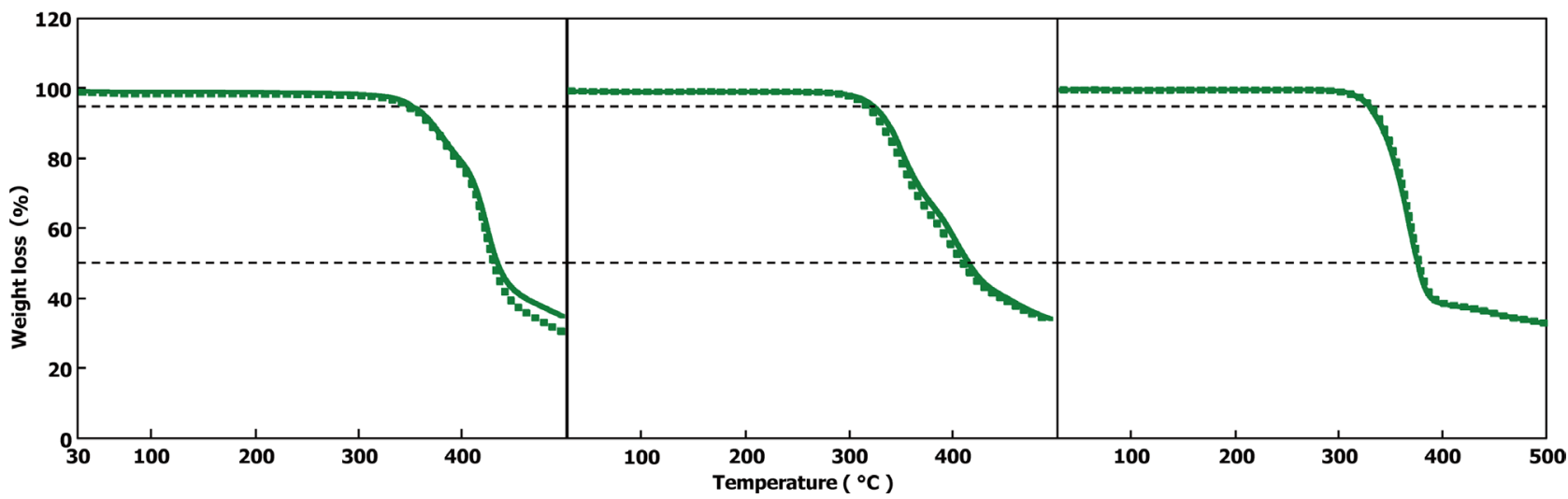

Figure 4. TGA curves of the PUIEs: solid line (before PUIE-ODPA) and dotted line (after PUIE-ODPA).

Table 3. Expression of the thermoplasticity of PUIEs.

\begin{tabular}{cc}
\hline Sample & Thermoplasticity $^{\mathrm{a}}$ \\
\hline ODPA-PTMG & 0 \\
PMDA-PTMG & $\times$ \\
ODPA-PCL & 0 \\
PMDA-PCL & $\times$ \\
ODPA-PCD & 0 \\
PMDA-PCD & $\times$ \\
\hline
\end{tabular}

${ }^{a} O$ : Thermoplasticity, $x$ : No Thermopasticity. 


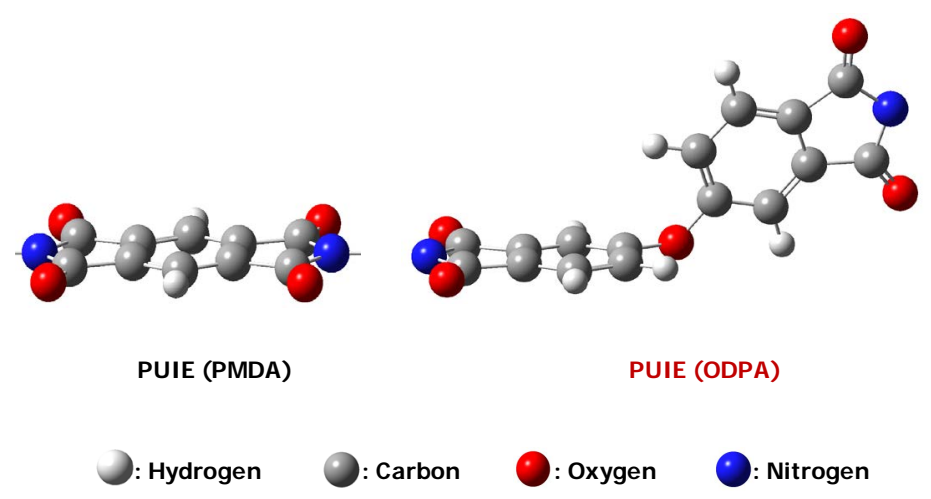

Figure 5. Molecular models of ODPA and PMDA.

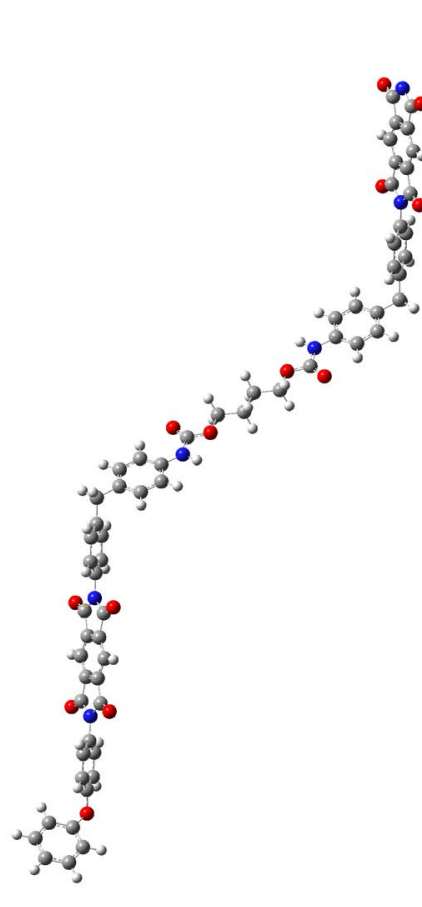

1. MDI-PTMG-ODA-PMDA

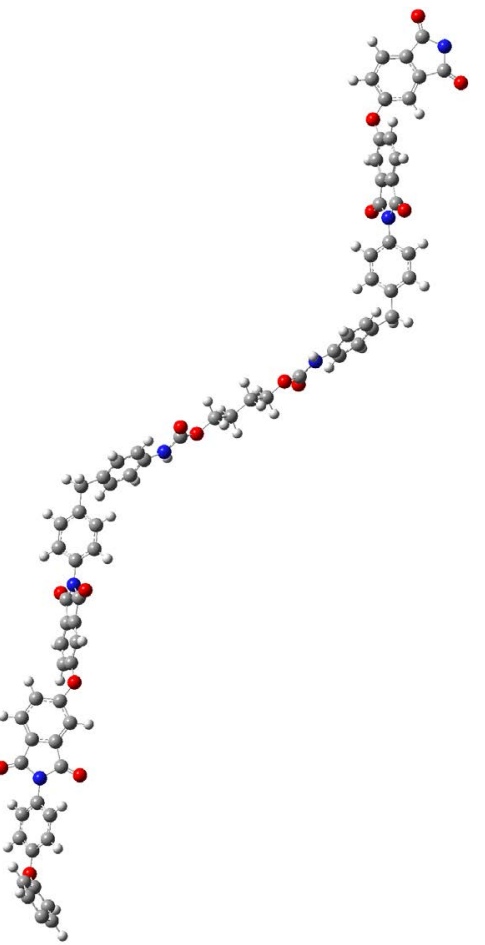

2. MDI-PTMG-ODA-ODPA

\footnotetext{
: Hydrogen $O$ : Carbon $\quad$ : oxygen $\quad$ Nitrogen

Figure 6. Molecular models of ODPA-containing PUIE and PMDA-containing PUIE.
}

\section{Conclusion}

The expression of PUIE thermoplasticity for the various PUIEs synthesized by solution-phase polymerization was investigated. The thermoplasticity of ODPA-containing PUIEs was identified by the heating tests, swelling tests, tensile tests, DSC, DMA, and TGA of the PUIEs both before and after a molding treatment. We found that using ODPA as the acid anhydride greatly increased the thermoplasticity of the synthesized PUIE. The knowledge obtained in this study will be useful for designing TPUIEs for various applications. 


\section{Acknowledgements}

The authors are grateful to Mr. Tomohiro Nishio for taking measurements using dynamic mechanical analysis.

\section{References}

[1] Jeon, J.Y. and Tak, T.M. (1996) Synthesis and Characterization of Block Copoly(urethane-imide). Journal of Applied Polymer Science, 62, 763-769. https://doi.org/10.1002/(SICI)1097-4628(19961031)62:5<763::AID-APP7>3.0.CO;2$\underline{\mathrm{U}}$

[2] Zuo, M. and Takeichi, T. (1997) Novel Method for the Preparation of Poly(urethane-imide)s and Their Properties. Journal of Polymer Science Part A: Polymer Chemistry, 35, 3745-3753. https://doi.org/10.1002/(SICI)1099-0518(199712)35:17<3745::AID-POLA14>3.0.C $\underline{\mathrm{O} ; 2-\mathrm{D}}$

[3] Zuo, M., Xiang, Q. and Takeichi, T. (1998) Preparation and Properties of Novel Poly(urethane-imide)s. Polymer, 39, 6883-6889. https://doi.org/10.1016/S0032-3861(98)00179-7

[4] Asai, K., Onouchi, Y., Inoue, S. and Okamoto, H. (1998) First Evidence of Polyimide Elastomer Prepared from Polyurea and Pyromellitic Dianhydride. Chemistry Letters, 3, 227-228. https://doi.org/10.1246/cl.1998.227

[5] Zuo, M. and Takeichi, T. (1999) Preparation and Characterization of Poly(urethane-imide) Films Prepared from Reactive Polyimide and Polyurethane Prepolymer. Polymer, 40, 5153-5160. https://doi.org/10.1016/S0032-3861(98)00726-5

[6] Takeichi, T., Yamazaki, Y., Ito, A. and Zuo, M. (1999) Preparation and Properties of Porous Polyimide Films Prepared by the Pyrolysis of Poly(urethane-imide) Films. Journal of Photopolymer Science and Technology, 12, 203. https://doi.org/10.2494/photopolymer.12.203

[7] Philip Gnanarajian, T., Padmanabha Iyer, N., Sultan Nasar, A. and Radhakrishnan, G. (2002) Preparation and Properties of Poly(urethane-imide)s Derived from Amine-Blocked-Polyuretane Prepolymer and Pyromellitic Dianhydride. European Polymer Journal, 38, 487. https://doi.org/10.1016/S0014-3057(01)00216-6

[8] Lin, M.F., Shu, Y.C., Tsen, W.C. and Chuang, F.S. (1999) Synthesis of Polyurethane-Imide (PU-Imide) Copolymers with Different Dianhydrides and Their Properties. Polymer International, 48, 433-435. https://doi.org/10.1002/(SICI)1097-0126(199906)48:6<433::AID-PI161>3.0.CO;2-1

[9] Asai, K., Inoue, S. and Okamoto, H. (2000) Preparation and Properties of Imide-Containing Elastic Polymers from Elastic Polyureas and Pyromellitic Dianhydride. Journal of Polymer Science Part A: Polymer Chemistry, 38, 715-723. https://doi.org/10.1002/(SICI)1099-0518(20000215)38:4<715::AID-POLA6>3.0.CO; 2-8

[10] Takeichi, T., Yamazaki, Y., Fukui, T., Matsumoto, A. and Inagaki, M. (2000) Preparation and Characterization of Porous Carbonized Films by the Pyrolysis of Poly(urethane-imide) Films. Tanso, 195, 388-394. https://doi.org/10.7209/tanso.2000.388

[11] Takeichi, T. and Arimatsu, K. (2001) Preparation and Properties of Poly(urethane-imide) Films from Polyether Polyol: An Attempt to Nanoporous Polyimide Films. Journal of Photopolymer Science and Technology, 14, 67-72. 
https://doi.org/10.2494/photopolymer.14.67

[12] Liu, J. and Ma, D. (2002) Study on Synthesis and Thermal Properties of Polyurethane-Imide Copolymers with Multiple Hard Segments. Journal of Applied Polymer Science, 84, 2206-2215. https://doi.org/10.1002/app.10421

[13] Takeichi, T., Ujiie, K. and Inoue, K. (2005) High Performance Poly(urethane-imide) Prepared by Introducing Imide Blocks into the Polyurethane Backbone. Polymer, 46, 11225-11231. https://doi.org/10.1016/j.polymer.2005.09.075

[14] Qiu, F., Yang, D. and Li, P. (2009) Synthesis, Characterization, and Thermos-Optical-Properties of Poly(Urethane-Imide) Based on Azo-Disperse Dye in Its Side Chains. Iranian Polymer Journal, 18, 651-661.

[15] Kogiso, T. and Inoue, S. (2010) Synthesis and Properties of Elastic Polyurethane-Imide. Journal of Applied Polymer Science, 115, 242-248. https://doi.org/10.1002/app.31126

[16] Zang, L., Han, X., Xiao, W. and Li, J. (2011) Synthesis and Property Study of a New Polyurethane-Imide. Huagong Jinzhan, 30, 2491-2494.

[17] Sang, X., Wang, R., Chen, X., Zang, L., An, M. and Shen, Y. (2011) A Review on Synthesis and Property of Polyurethane-Imide. Advanced Materials Research, 284, 1746-1749. https://doi.org/10.4028/www.scientific.net/AMR.284-286.1746

[18] Ueda, T., Nishio, T. and Inoue, S. (2017) Influences of Diamines on the Morphologies and the Chemical, Thermal, and Mechanical Properties of Polyurethane-Imide Elastomers. Open Journal of Organic Polymer Materials, 7, 47-60. https://doi.org/10.4236/ojopm.2017.74004

[19] Salary, J. and Smith, C.H. (1975) Polyurethane/Imide Modified Foam. Journal of Cellular Plastics, 11, 262. https://doi.org/10.1177/0021955X7501100505

[20] Sang, X., Chen, X., Hou, G. and Yu, S. (2011) Preparation and Properties of RigidPolyurethane-Imide Foams. Advanced Materials Research, 150, 1119.

[21] Muller-Cristadoro, A. and Prissok, F. (2014) Method for Production of Polymer Foams Comprising Imide Groups. U.S. Pat. Appl. Publ, US 20140042356 A1.

[22] Wang, Y., Tian, H., Bian, Q., Xiang, A., Ge, X. and Liu, G. (2015) Effect of Trolamine and Dibutyltin Dilaurate on the Structure and Properties of Polyurethane-Imide Foams. Cellular Polymers, 34, 119-135.

[23] Yeganeh, H., Barikani, M. and Noei Khodabadi, F. (2000) Synthesis and Properties of Novel Thermoplastic Poly(urethane-imide)s. European Polymer Journal, 36, 2207-2211. https://doi.org/10.1016/S0014-3057(99)00284-0

[24] Jiang, B., Hao, J., Wang, W., Jiang, L. and Cai, X. (2001) Synthesis and Thermal Properties of Poly(urethane-imide). Journal of Applied Polymer Science, 81, 773-781. https://doi.org/10.1002/app.1494

[25] Yeganeh, H. and Shamekli, M.A. (2004) Poly(urethane-imide), a New Generation of Thermoplastic Elastomers with Enhanced Thermal Stability. Polymer, 45, 359-365. https://doi.org/10.1016/j.polymer.2003.11.006

[26] Tai, M.-H., Huang, S.-H., Liu, S.-J., Chen, C.-J., Chen, P.-J. and Chen, S.-H. (2008) Synthesis and Properties of Poly(urethane-imide) Interpenetrating Network Membranes. Desalination, 233, 191-200. https://doi.org/10.1016/j.desal.2007.09.042

[27] Li, Z., Xu, T., Sun, J., Zhang, F., Sun, B. and Wang, Z. (2008) Preparation and Properties of Polyurethaneurea-Imide Elastomer. China Synthetic Rubber Industry, 31, 312.

[28] Gnanasekaran, D. and Reddy, B.S.R. (2011) Synthesis and Characterization of Poly(urethane-imide) POSS Nanocomposites. Nanotechnology Conference and 
Expo, Boston, 13-16 June 2011, Vol. 1, 445-448.

[29] Xu, T., Yan, W., Wang, S.-J., Li, Z.-F., Sun, B.-Q. and Wang, M.-X. (2008) Synthesis of Polyure Thane Modified Bismaleimide (UBMI) and Polyurethane-Imide Elastomer. Journal of Polymer Science, 26, 117.

[30] Mifune, Y., Nishio, T., Shibata, J. and Ueda, Y. (2010) Jpn. Kokai Tokyo koho JP 201022567.

[31] Song, J., Chen, G., Wu, G., Cai, C., Liu, P. and Li, Q. (2011) Thermal and Dynamic Mechanical Properties of Epoxy Resin/Poly(urethane-imide)/Polyhedral Oligomeric Silsesquioxane Nanocomposites. Polymers for Advanced Technologies, 22, 2069-2074. https://doi.org/10.1002/pat.1722

[32] Patel, B.P., Patel, H.S. and Patel, D.B. (2011) Glass Reinforcement of Epoxy Resin Based Poly(urethane-imide)s. International Journal of Plastics Technology, 15, 163-173. https://doi.org/10.1007/s12588-012-9021-9

[33] Gui, D., Gao, X., Hao, J. and Liu, J. (2014) Preparation and Characterization of Liquid Crystalline Polyurethane-Imide Modified Epoxy Resin Composites. Polymer Engineering \& Science, 54, 1704-1711. https://doi.org/10.1002/pen.23712 